\title{
ArcGIS-mapping to sustainable wastewater management in Greece: siting artificial wetlands systems in a biosystem
}

\author{
Kariotis S. ${ }^{1}$, Giannakopoulos E. ${ }^{2 *}$ and Kalavrouziotis I.K. ${ }^{1}$ \\ ${ }^{1}$ School of Science and Technology, Hellenic Open University, Tsamadou 13-15 \& Agios Andrea, 26222 Patras, Greece \\ 2Department Biosystems \& Agricultural Engineering, School of Agricultural Sciences, University of Patras, Mesologhi, 30200, Greece \\ Received: 08/03/2020, Accepted: 02/01/2021, Available online: 05/03/2021 \\ *to whom all correspondence should be addressed: e-mail: v.giann@yahoo.com \\ https://doi.org/10.30955/gnj.003303
}

\section{Graphical abstract}

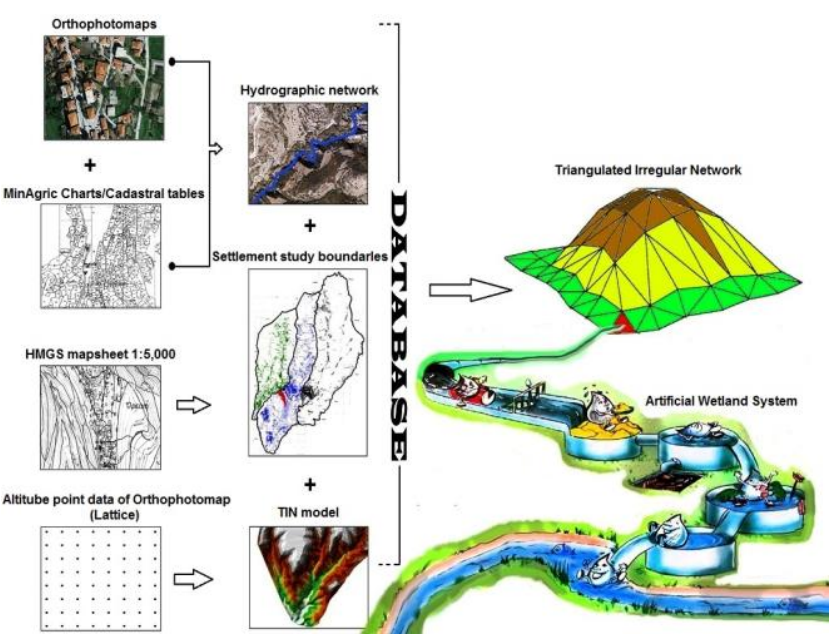

\section{Abstract}

In this work, the ArcGIS technology combines analogue and digital geospatial data to derive multiple resolution meshes with a triangulated irregular networks (TINs) approach that serves to integrate the geospatial data such as surface topography, hydro graphic features and land surface characteristics into an adaptive representation of a basin biosystem. The ArcGIS model that has been developed is applied at the municipal level to a small remote settlement with less than 2000 people in Northern Greece. The aim was a site assessment for constructing an artificial wetland (ATW) system as a viable solution to the wastewater management problem and protection of biosystems. This study demonstrates that there are discrepancies in Greece between the existing open geospatial data and on the basis of the results from our study we can conclude that this combination of local maps and geographic information in ArcGIS with a TIN approach increases our knowledge of the physical terrain. It accordingly facilitates the analysis and implementation of action plans by selecting suitable sites for construction of ATW systems in small remote settlements. We moreover discuss problems regarding spatial data quality and scale and provide suggestions for improvement while the desktop classification steps can be easily reproduced for other data-similar countries.

Keywords: ArcGIS, wastewater management, pollution control technology, artificial wetlands (ATW) systems, biosystems.

\section{Introduction}

Waste management is a global issue that requires maximum attention (Charisios et al., 2013; Giannakopoulos et al., 2017; Papamanolis et al., 2018). One of the most important decisions made by municipalities nowadays is the selection of a landfill site or developing natural systems such as stabilisation ponds for domestic wastewater treatment (Gemitzi et al., 2007; Longley et al., 2010). These decision must take many factors into account such as environmental pollution, reduced land availability for landfills, increasing political and social opposition to the establishment of landfill sites, increasing population densities, government regulation, government and municipality funding, and urbanisation (Malczewski, 1997; Rushbrook and Pugh, 1999). This evidently requires the processing of massive amount of spatial data. Various landfill siting techniques have been occasionally developed for this purpose, e.g. siting techniques combining multi-criteria decision analysis (MCDA) and GIS (Akbari et al., 2008; Choudhury et al., 2012; Kontos et al., 2003; Zamorano et al., 2008). According to Michaels (1991) a GIS approach (often referred as ArcGIS) can be used to combine various demographic, geological, land use and census tract maps for applying landfill criteria and finding suitable areas to install a landfill (Gemitzi et al., 2007; Longley et al., 2011). Another GIS approach employed wetland type models, disturbance indices and identified priority wetlands through threatened faunal species associations by using existing data. (Van Deventer et al., 2015).

According to Alemany et al. (2005) ATM systems constitute the optimal solution for protecting the environment of small settlements and the site suitability must be assessed on scale based indexes that measure the risk of contamination in the following environmental components (Dai et al., 2016). On the other hand, TINs 
have become increasingly popular because of their efficiency in storing data and their simple data structure for accommodating irregularly spaced elevation data. Advantages have also been found when TIN models are used in inter-visibility analyses on topographic surfaces, the extraction of hydrological terrain features and other applications (Lee, 1991). One of the advantages of TIN structure is that it includes the original points on the ground, thus providing a useful way for checking the accuracy of the model and the data structure makes it easier to calculate the slope (Wu and Amaratunga, 2003).

In this article, the ArcGIS model combines analogue and digital geospatial data by deriving multiple resolution meshes (with the TINs approach) into an adaptive representation of a basin. The developed ArcGIS model is applied at the municipal level to a small remote settlement with fewer than 2000 people in North Greece $\left(41^{\circ} 11^{\prime} 41.85^{\prime \prime} \mathrm{N}, 23^{\circ} 35^{\prime} 34.12^{\prime \prime} \mathrm{E}\right)$, where there is no waste processing system. The aim of the site assessment is to construct an ATW system as a viable solution to the wastewater management problem in small remote settlement while the desktop classification steps can be reproduced easily for other data-similar countries.

\section{Materials and methods}

\subsection{1st Step: Parameterisation of the model}

One of the most prominent differences in the rapid development of GIS in decision - making in comparison to other design programmes is the database, which constitutes the interaction between the user and the spatial data by using the appropriate queries. According to Geoinfo Co. (1998) geospatial data is divided into two fundamental categories: discrete and continuous. In practice, a raster model is related to continuous data and a vector model is related to discrete data (Kalogeropoulos and Chalkias, 2012). In this paper, the triangles of a ground terrain model in the TIN format only exist in the digital model, not on the actual ground. It is just like the contouring lines and represents the surface as a set of non-overlapping contiguous triangular facets of irregular sizes and shapes (Peucker et al., 1978) whilst the conversion from the analogue to the digital format includes scanning schematics like MinAgric charts (Surveying Division of the Ministry of Rural Development and Food, former Agricultural or prefectural decisions on settlement boundaries) and vectorisation (conversion of raster data into vector data) where required (Tsouhlaraki and Ahileos, 2010). It is imperative in this case to homogenise this data into a single reference system that must include some form of geo-referencing so that different information data can be connected via a common geographical location. Decision- making is all about choices. In particular, GIS provides spatial item selection that is selected by location or attributes. Some of the main examples of such functions are the selection of entities, the creation of buffer zones, the dissolution of entities and the creation of Thiessen polygons. In the case study, the eligible sites fall within the boundaries of the study area, which are also the administrative boundaries of the settlement. An additional criterion is that the site is in such a position that allows for the transportation of waste solely via gravity (minimising operational cost). Accordingly, the desirable altitude of the unit should be lower than that of the lowest part of the designated boundaries in the settlement, according to the prefectural planning decisions which demarcate the settlement. Moreover, spatial queries were submitted so that the information returned fulfils the above requirements.

All criteria entered in the ArcGIS information system aimed at minimizing soil-related works (e.g. earthworks for installations) as well as to avoid using mechanical equipment (e.g. construction of pump stations), and also keep the related cost for remunerations of third parties to the minimum possible (e.g. very few compulsory purchases of land). The aim was also to avoid the occupation of forest lands when transporting wastewater from the settlement to the processing unit of the artificial wetland. The evaluation of above criteria is based on the use of environmental indices to provide a quantitative assessment of the possible environmental interactions between an artificial wetlands systems and potentially affected environmental components because of the sitting of the artificial wetland systems in a biosystem. This method evaluates the treated municipal wastewater as non-hazardous waste by Urban Wastewater Directive 271/91 (EC, 1991). It is thus applicable in the European Union, and in any other country where similar legislation exists, or where there is no legislation or where the legislation is less prescriptive than this Directive. Thus, after the secondary treatment, the treated water can be released and through the free flow reach the ultimate recipient (e.g. a lake or river), without any further transportation installation for the treated water produced.

\subsection{2nd Step: Cartographic background creation}

The current map projection system in Greece is the Transverse Mercator Projection $6^{\circ}$ (TM_87) and Datum, GGRS_87 with GRS_80 ellipsoid (Kariotis and Panagiotopoulos, 2013). HMGS' schematic charts on a scale of 1:5,000 were used for the vectorisation of the road and hydro graphic network. The map also depicts the buildings of the settlement and the contour lines with a contour interval of $4.00 \mathrm{~m}$. The aerial photographs were taken in 1977, which is quite a while ago to allow for modern planning. The alternative locations selection model for the placement of the wetland system is covered in the aforementioned horizontal accuracy. The HMGS schematic charts are in azimuthal projection (Hatt) with Bessel as a reference ellipsoid. Greece has been divided into large 1:100,000 map sheets, each of which has its own Cartesian coordinate system. The 1:5,000 HMGS charts refers to $1: 100,000$ map sheets where the map sheet centre distance is per 30' (large map sheets). Hatt was converted to TM_87 (GGRS_87). Upon enquiring at the City Planning Department we found that the settlement lacked town planning. It is however included in settlements where the building terms and boundaries are defined by the Prefect of Serres' decision and are 
accompanied by $1: 5,000$ charts. The background used is derived from 1:5,000 charts by the Hellenic Military Geographical Service (HMGS) upon which boundaries of plots have been transferred with relatively low accuracy from the schematic charts by the Surveying Division of the Ministry of Rural Development and Food. It was used for the definition of the settlements (existing and extensions) so that the placement may be carried out at a similar predicted distance. These charts are in azimuthal projection and Bessel ellipsoid referenced in 1:20,000 map sheets, where the map sheet centre distance is per $6^{\prime}$ (small map sheets). Hatt was converted to TM_87 (GGRS_87) and compared to the Prefect's decision city planning charts. The Orthophotomaps of the National Cadastre and Mapping Agency are fairly recent (dating to 2007-2009) upon which the National and Forest Cadastre is based. They have been drafted with the current Greek projection system in mind. The information drawn from the data vectorisation presents the layout of the cadastral squares within the settlement and accordingly the production of the existing road network. At the same time, they were used to locate forest areas so that siting in said areas could be avoided. The MinAgric schematic charts (after the appropriate conversion) were compared and contrasted with the orthophotomaps so that public areas may be selected (to avoid expropriation) as a financial factor in the siting. Altitude data was drawn from the Lattice Points files, with horizontal distance per $20 \mathrm{~m}$, to create the Digital ground model. 421,501 altitude points were used and the relief of the terrain was illustrated in the TIN format (triangulated irregular network) by creating 51,676 triangles.

Table 1. A holistic approach to sustainable. Selection and classification of criteria types

\begin{tabular}{|c|c|}
\hline Criteria & Selection and classification of criteria types \\
\hline \multirow[t]{2}{*}{ Topography } & $\begin{array}{l}\text { 1. The search boundaries for the placement area and the settlement boundaries, which were assembled from } \\
\text { charts by the Surveying Division of the Ministry of Rural Development and Food (MinAgric) and the Hellenic } \\
\text { Military Geographical Service }\end{array}$ \\
\hline & 2. Treatment plant altitude below the minimum altitude of the settlement \\
\hline \multirow{2}{*}{ Environmental } & $\begin{array}{l}\text { 3. The minimum altitude of the settlement to create a network of waste pipes that function with free flow (gravity) } \\
\text { from every part of the settlement (operational economy) }\end{array}$ \\
\hline & $\begin{array}{l}\text { 4. Area inspection so that it is outside the forests and areas with highest environmental protection (Natura } 2000 \\
\text { network) }\end{array}$ \\
\hline Hydrologic & 5. Hydro graphic network \\
\hline Economic & $\begin{array}{l}\text { 6. A check of property ownership (public land or ownership requiring expropriation, time delay, social and financial } \\
\text { problems) }\end{array}$ \\
\hline \multirow[t]{2}{*}{ Other } & $\begin{array}{l}\text { 7. Surface area measurement }\left(>3000 \mathrm{~m}^{2}\right) \text { (changeable element depending on the geometric characteristics of the } \\
\text { plant in question) }\end{array}$ \\
\hline & 8. Slope of terrain $(=<10 \%)$ (specifications and economy of construction and operation) \\
\hline
\end{tabular}

\subsection{3rd Step: Plotting artificial wetlands plants (ATWs) with GIS Tool}

The study area was the remote settlement at OPEINH $\left(41^{\circ} 11^{\prime} 41.85^{\prime \prime} \mathrm{N}, 23^{\circ} 35^{\prime} 34.12^{\prime \prime} \mathrm{E}\right)$ in the Serres Municipality of Northern Greece. The designing of the plant factors in unit isolation, so that functions won't be interrupted in the cases of any maintenance work or technical issues. The wastewater will be transported via gravity through the sewerage network of the settlement into the inlet of the plant where the grates will be located. After measuring the flow rate, wastewater will be collected in the anaerobic primary sedimentation tank. As a secondary processing method, we have chosen the vertical flow method which is then diverted to tertiary treatment and ultimately to the final recipient, the stream of Agioi Anargyroi. It should be mentioned here that all lakes in the area are protected by the Natura 2000 network and are areas of the highest environmental protection (e.g., in the National Park of Eastern Macedonia and Thrace) classified as Zone A (Greek Ministry of Environment, Physical Planning and Public Works, 1996), and consequently cannot directly receive effluent discharges. Furthermore, in order to avoid any undesirable effects upon the existing populated areas through the presence of a wastewater treatment system, it is necessary to situate such facilities at least $500 \mathrm{~m}$ away from villages or city limits. Greek law does not specify minimum distances from city limits for wastewater treatment facilities. This distance was accordingly selected on the basis of Greek Governmental Ministry Decision 114218/97 (1997) for sanitary landfills, while the geometric characteristics of the plant and the possible altitude restrictions result from the selection method. We also need to consider the financial aspect of these issues not only when in relation to the construction, but also the operation of the plant. The location of the treatment plant was accordingly selected upon the following criteria, Table 1.

\section{Results and discussion}

\subsection{Logical analysis}

The preceding analysis indicates the procedures observed for creating the necessary cartographic background. Environmental management is to a large degree a spatial procedure. The data used for the placement study requires a clear definition of the criteria and characteristics these places should govern. The combinational, multi-parameter and multi-level interpretation of map data is therefore required for rejecting or accepting alternate site locations. In the placement study, alternative sites that fulfil the criteria 
are selected and eventually the most appropriate site is chosen. The slope of the land, the distance from the settlement (which also affects the anthropogenic factor) and the possible expropriation required for the construction, all play a major role in the construction cost (see Table 1). The use of GIS deals with spatial and descriptive issues without substituting the researcher, but by minimising the alternate site research time and producing results that fulfil the required criteria. An interaction between the researcher and the software accordingly develops where the researcher defines the criteria and the software essentially carries out the repetitive testing processes for arriving at one or more optimal results (Longley et al., 2011).

\subsection{Point selection}

421,501 points were used in the $X, Y$, and $Z$ format for the terrain rendering. ArcGIS was used with EGSA_87 as the projection system. The points were input in such a manner so that a simple data file can be converted into usable information, which is exportable for file shaping. The eligible sites must fall within the boundaries of the study area, which are also the administrative boundaries of the settlement. An additional criterion is that the site is in such a position that allows for the transport of the waste via gravity alone (minimising operational cost). The desirable altitude of the unit should therefore be lower than that the lowest part of the designated boundaries in the settlement, according to the prefectural planning decisions which demarcate the settlement. Spatial queries were submitted so that the information returned fulfils the above requirements (see Table 1). The queries were submitted in order to provide a circumferential safety margin in the rendering of the terrain (i.e. there will be no gaps in the terrain). From the first query, we discern that there are 1,413 sites within the settlement boundaries. Since it is classified by altitude, it ensures that the site with the highest altitude is $Z=899.64 \mathrm{~m}$ and the lowest is $Z=711.71 \mathrm{~m}$. A second query was thus submitted to the system that deals with the selection of sites with an altitude lower than $711.71 \mathrm{~m}$ (select by Attributes) out of the total number of areas introduced into the system. The sites were then limited to the southern side of the settlement. This area meets the above requirements. Upon arriving at this result, the third spatial query was introduced for selecting the areas that are included within the study area, which is within the administrative boundaries of the settlement (Tsouhlaraki and Ahileos, 2010). The selection of areas within a $50 \mathrm{~m}$ radius from the administrative boundaries of the settlement is recommended (and applied in this study) for ensuring that the relief of the terrain corresponds to the boundaries of the area and there are no gaps. The result is the blue highlighted area in Figure 1 with the procedure mentioned above; the initial 421,501 points have been limited to 25,854 while the altitude variation ranges between 711.70 and $348.68 \mathrm{~m}$.

\subsection{TIN creation}

The Delaunay triangulation is fundamental in computational geometry and is used for terrain modelling. TIN creation is aimed at digitally rendering the terrain and contributes to spatial selection, since it calculates the slope of the terrain. With a similar query therefore, polygons with less than a $10 \%$ ground gradient can be selected and the researcher can limit the research to alternative positions that shall emerge (Astaras et. al., 2011). The application of the algorithm indicates that 51,676 triangles have been created covering the area, the slope of each has been calculated and is expressed as a percentage (\%) and the orientation is also calculated. The result in Figure 2 includes triangles larger than $200 \mathrm{~m}^{2}$ (gravy areas). Provided that the primary points are distributed in grid data per $20 \mathrm{~m}$ along $X$ and $Y$, the triangles created shall have a maximum area of $200 \mathrm{~m}^{2}$. Any larger triangle is located circumferentially of the area in question and contains incorrect information. With the fourth query, only triangles with an area $\leq 200 \mathrm{~m}^{2}$ are requested. Out of 52,676 triangles, 50,609 were selected with an area of $\leq 200 \mathrm{~m}^{2}$, which implies that the gravy areas in Figure 2 were removed.

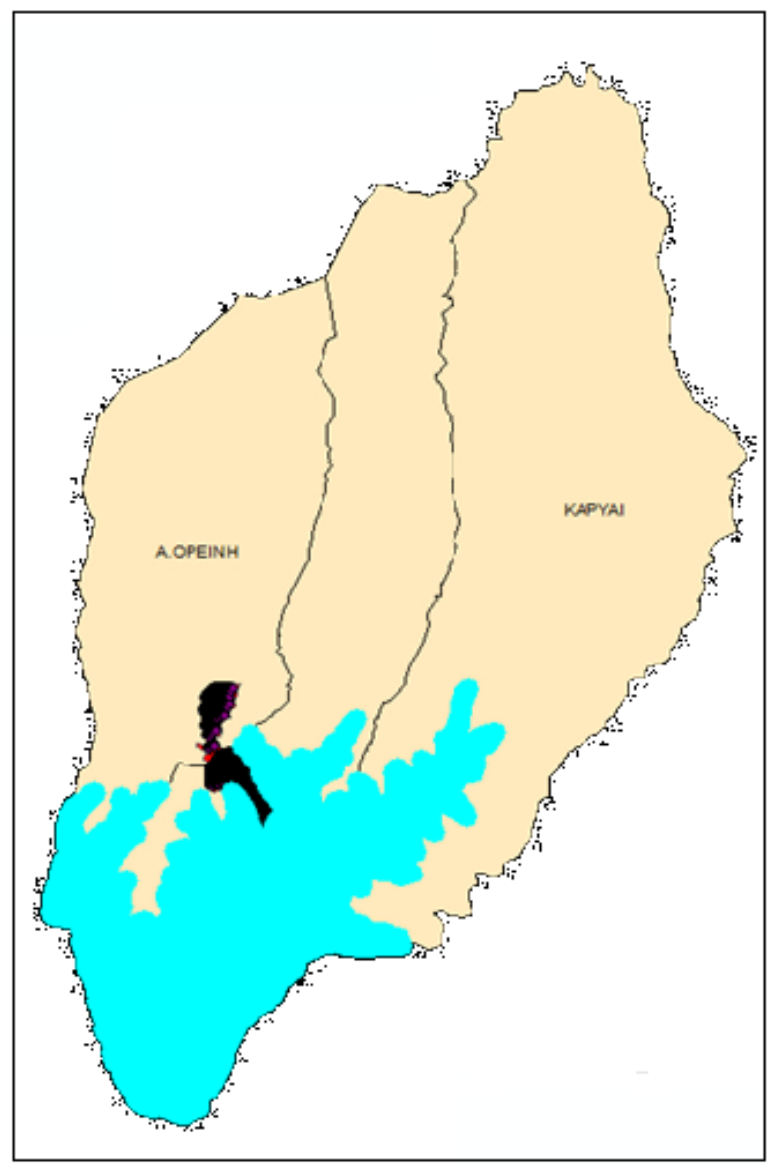

Figure 1. Results (blue area) based on the third spatial query (location-criterion)

Figure 3 indicates the area without such errors. The next selection criterion is the slope that was defined at $\leq 10 \%$ as an economy feature in the earthworks, with the fifth query, only the triangles with $\leq 10 \%$ slope were requested. 
The result is depicted in Figure 4, where only 1,023 triangles were chosen out of 50,609 triangles and are highlighted in blue.

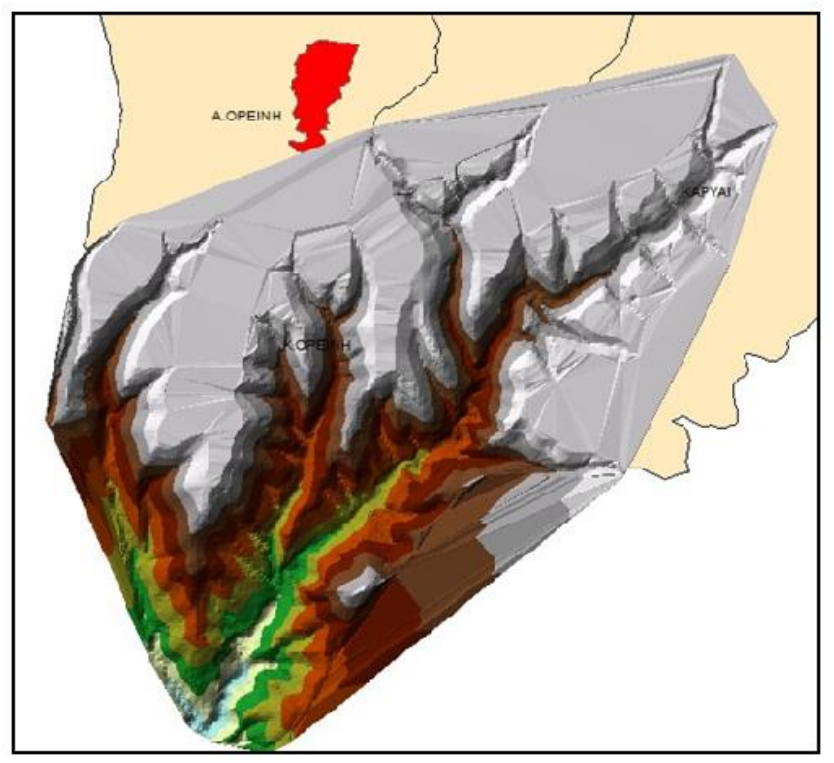

Figure 2. Colour gradation of altitude result

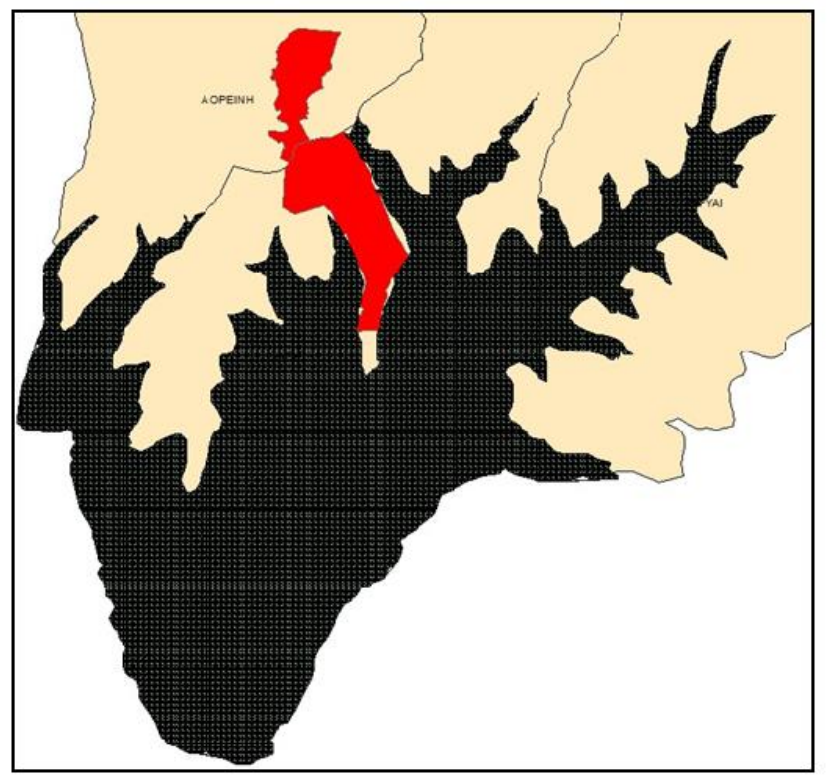

Figure 3. TIN debugging

The next task is to integrate adjacent triangles so that there is a single polygon from which the area will initially be assessed. Following integration, 551 polygons were created out of the original 1,023 triangles. It is discernible from the table sorting by AREA in descending order that there are only 6 integrated locations with an area $>3,000$ $\mathrm{m}^{2}$ (Figure 5). Through geodata.gov.gr we can reject additional areas downstream by uploading the hydro graphic network and importing the shape file into the working environment (see alternatives in Figure 5).

\subsection{Analysis of alternatives}

Table 2 summarises the analysis of the alternatives that are presented in Figure 5.

If the query area is expanded to include areas under 3,000 $\mathrm{m}^{2}$, two more interesting alternatives arise, which are not only adjacent to the final recipient but also connected to neighbouring areas and therefore eligible for the location of the unit.

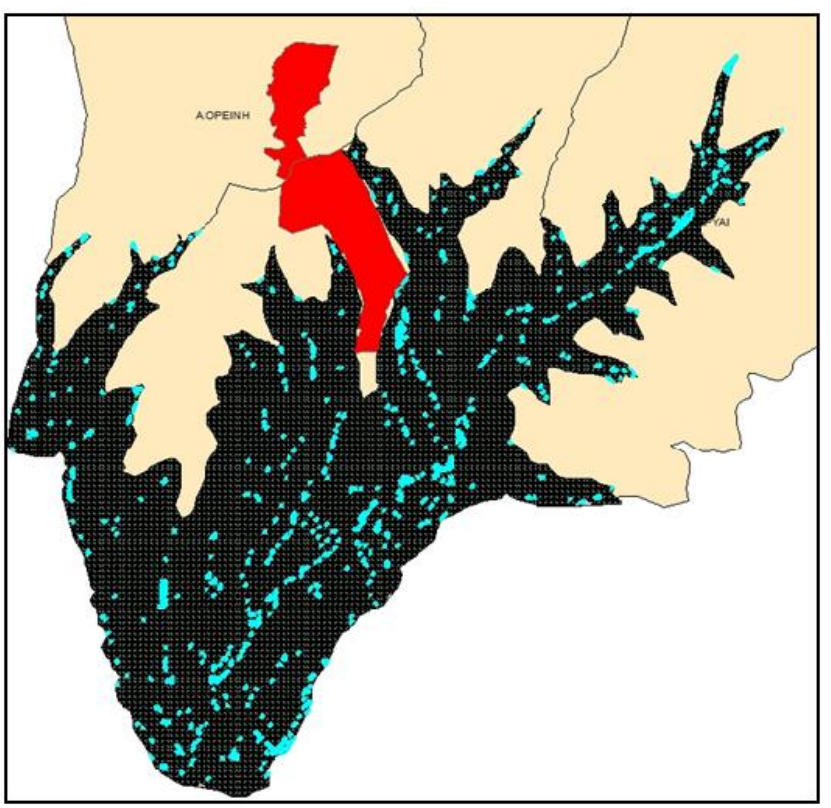

Figure 4. Triangles with $\leq 10 \%$ slope

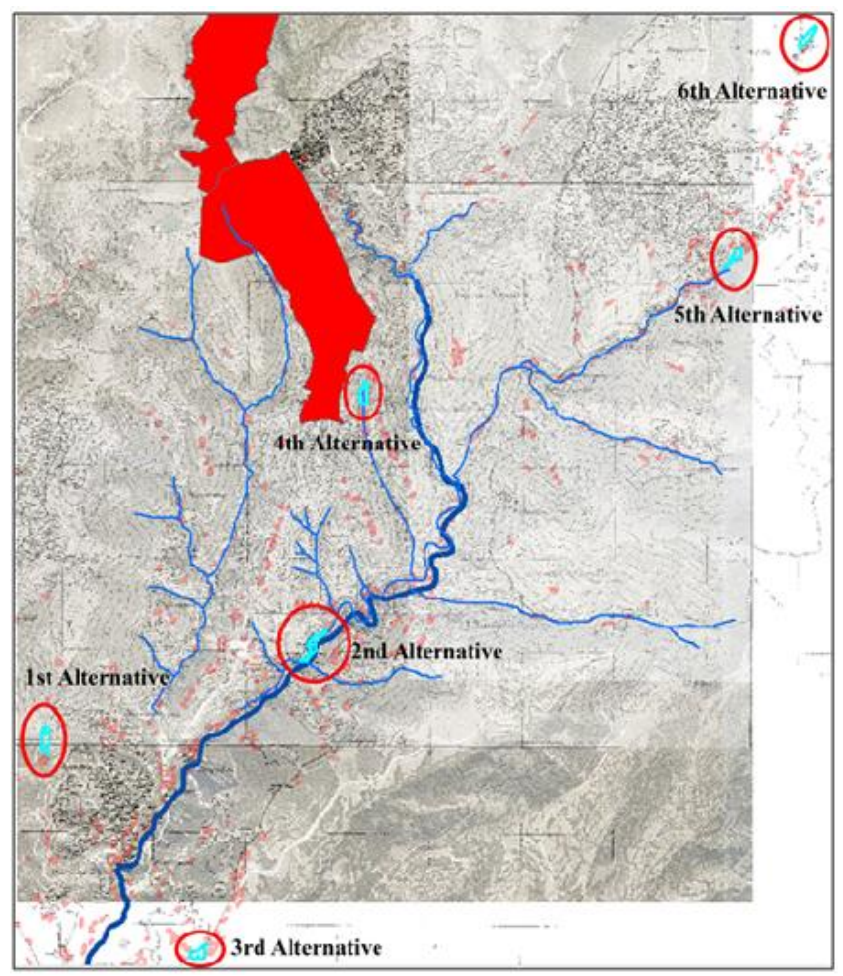

Figure 5. Six integrated locations with an area $>3,000 \mathrm{~m}^{2}$. The blue line depicts the stream of Agioi Anargyroi

An important finding resulting from the data combination is that the hydro graphic network has not been properly applied in the HMCO orthophotomaps. This imperfection 
is probably due to the fact that low scale schematic charts (e.g. 1:50,000) were used during the vectorisation resulting in a generalization of the pathways. Because the hydro graphic network from geodata.gov.gr was not considered to be fully applicable to the situation at hand, an information source was sought from the HMGS 1:5,000 schematic charts. After correction and the georeferencing processing of map sheet 3433_2 that covers the selected area, its adaptation to existing roads and buildings that are depicted in the HMCO schematic charts was tested. The hydro graphic network of the area was vectorised from HMGS 1:5,000 background so that the area could be more accurately researched. We can see that there is an area for further investigation close to $2^{\text {nd }}$ alternative, if the information levels for the hydro graphic network, properties, contour lines and HMCO schematic charts for the adjacent area are selected and we take into consideration the required dimensions derived from the corresponding calculation stage for the unit dimensioning. Moreover, it can be seen from the selected location that no properties are affected and the suggested facility is located near the final recipient and the unit can be built at different levels so as to further minimise the cost and at the same time, the consecutive transport of the wastewater from level to level shall be carried out by gravity, therefore eliminating the operational cost.

Table 2. Analysis of the alternatives that are presented in Figure 5

\begin{tabular}{cccc}
\hline Alternative & $\begin{array}{c}\text { Area } \\
\left(\mathbf{m}^{2}\right)\end{array}$ & $\begin{array}{c}\text { Distance from } \\
\text { Settlement }(\mathbf{m})\end{array}$ & Decision \\
\hline $1^{\text {st }}$ & 4,800 & 2,200 & No expropriation is required, away from final recipient stream \\
\hline $2^{\text {nd }}$ & 4,600 & 1,100 & $\begin{array}{c}\text { Elongated layout, adjacent to recipient, satisfying distance from settlement }(1,100 \text { m). } \\
\text { Some expropriation is needed but there is a lot of communal space }\end{array}$ \\
\hline $3^{\text {rd }}$ & 4,000 & 3,000 & Rejected because it is downstream from the final recipient \\
\hline $4^{\text {th }}$ & 4,000 & 100 & $\begin{array}{c}\text { This alternative has many disadvantages: too close to the settlement. Complete } \\
\text { expropriation is required. Long pipe network for the waste transportation from the } \\
\text { west side of the settlement. }\end{array}$ \\
\hline $5^{\text {th }}$ & 3,200 & 2,000 & Rejected because it is downstream from the final recipient. \\
\hline $6^{\text {th }}$ & 3,000 & 2,750 & Rejected because it is downstream from the final recipient.
\end{tabular}

\section{Discussion}

\subsection{Investigating the creation of cartographical data in Greece}

The aforementioned process has demonstrated the contribution of the Geographical Information Systems to decision-making. The role of the researcher is still pivotal at every stage in the study, from data selection to criteria definition and checking results. The process shows that an important factor in selecting the placement location is the selection of the data sources. The creation of a valid and up-to-date cartographical data background is a crucial condition of the study in defining alternative locations using GIS. It is preferable for the TIN creation to employ primary data (Lattice) over data such as contour lines. The correlation of the MinAgric Surveying Division charts and the city planning charts by prefectural decision requires the investigation and selection of fixed points to be used and a particular conversion method in the GGRS_87 system. It has also been established in Greece that there are discrepancies between the existing open geospatial data, the hydro graphic network and HMGS charts. These have probably been caused by low scale vectorisation and are suitable for cartographic and not topographic purposes.

Where a drone (use of new technology) is available to the user, it would then be prudent to depict the current situation, so that the final delimitation of the area being investigated is on a larger scale $(1: 1,000)$. From the results of the drone survey, we can: (i) clearly define the route of the final recipient; (ii) depict the relief of the terrain with satisfactory accuracy; (iii) take into account the structure of the forest vegetation; (iv) limit expropriation (if existent); and ( $v$ ) format the final outline of the installation area.

\subsection{Cartographic recommendations to state and local authorities - challenges and opportunities}

A combined cartography and geographic information system is not available in Greece for generating geospatial data. The State and the Local Authorities should organise, enrich and complete the geospatial data in the most accurate way possible so that it can be readily used by researchers and services without requiring additional work. The final cartographic background must be provided with the suitable data so that locations that fulfils the following conditions can be found: Environmental conditions, such as: eliminating forest areas; minimal distances from settlements; minimal distance from national or rural networks; eliminating locations that have visual contact with settlements or roads; and minimising construction costs by using the ground relief for fewer earthworks; searching for non-private areas to avoid expropriations; minimising the access costs by being a small distance from the existing road network; minimising the cost for depositing the processed waste by being a small distance from the recipients; avoiding the use of pumping compounds; and avoiding the creation of siphons. Local Authorities should study and document settlements with less than 2,000 residents where natural waste processing systems can be constructed and integrate such projects into EU programmes aimed at environmental protection. The use of "drone" technology is recommended for checking and updating the location 
result in order to depict the existing situation on a conclusive study scale and research the final delimitation of the area.

\section{Conclusion}

Geographical Information Systems or Decision Making Systems assist the researcher with the objective definition of alternative locations for the construction of waste processing units by implementing the given criteria in spatial results. Based upon the results obtained from our study, a combined cartography and geographic information system (GIS) does not exist in Greece for generating geospatial data and an ArcGIS approach is often used. Consequently, this combination of local maps and geographic information in ArcGIS with a TIN approach increases our knowledge of the physical terrain, thus facilitating the analysis and implementation of action plans selecting suitable sites such as the construction of an ATW system in biosystems. Moreover, problems regarding spatial data quality and scale are discussed and suggestions are provided for improvement, while the desktop classification steps can be reproduced easily for other data-similar countries.

\section{ArcGIS license}

Software License Agreement No. 2011MLK2049/Hellenic Open University

\section{Conflict of Interest}

The authors declare no conflict of interest, financial or otherwise.

\section{Acknowledgments}

The authors acknowledge the Regional Authority of Central Macedonia in Greece for its support and providing the necessary data for the study area.

\section{References}

Akbari V., Rajabi A.M., Chavoshi H.S. and Shams R. (2008), Landfill site selection by combining gis and fuzzy multi criteria decision analysis, case study: Bandar Abbas, Iran, World Applied Science Journal, 3 (1), 39-47. ISSN 1818-4952.

Astaras T., Oikonomidis D. and Mouratidis A. (2011), Digital Cartography and Geographic Information Systems, Disigma Publications Thessaloniki, pp. 47-51. ISBN 978-960-9495-097.

Charisios A., et al. (2013), The use of multi-criteria decision analysis to tackle waste management problems: a literature review, Waste Management \& Research, 31(2), 115-129. https://doi.org/10.1177/0734242X12470203.

Choudhury C. and Das S. (2012), GIS and remote sensing for landfill site selection-A case study on Dharmanagar Nagar Panchayet, IOSR (International Organization of Scientific Research). IOSR Journal of Environmental Science, Toxicology and Food Technology, 1(2), 36-43. ISBN: 2319-2399.

EC. (1991), Council Directive 91/271/EEC of 21 May 1991 concer ning urban waste-water treatment. http://data.europa.eu/ eli/dir/1991/271/oj.

Gemitzi A., Tsihrintzis V., Christou O. and Petalas C. (2007), Use of GIS in siting stabilization pond facilities for domestic wastewater treatment, Journal of Environmental
Management, 82(2), 155-166. https://doi.org/10.1016/ j.jenvman.2005.12.022.

Geoinfo Co. (1998). Digital Data for Greece-GR Survey Data Base. Thessaloniki.

Giannakopoulos E., et al. (2017), Oxidation of municipal wastewater by free radicals mechanism. A UV/Vis spectroscopy study, Journal of Environmental Management, 195(2), 186-194. https://doi.org/10.1016/ j.jenvman.2016.07.055.

Greek Governmental Ministry Decision 114218/97 (1997), Document 1016 B'/17-11-1997 "Framework of Specifications and General Planning for the Management of Solid Wastes" (in Greek).

Greek Ministry of Environment, Physical Planning and Public Works. (1996). Joint ministerial Decision 5796/23-3-96. Official Gazette 854/B/ 16-9-1996 (in Greek).

Kalogeropoulos K. and Chalkias C. (2012), Modelling the impacts of climate change on surface runoff in small Mediterranean catchments: Empirical evidence from Greece, Water and Environment Journal 27(4), 505-5013. https://doi.org/ 10.1111/j.1747-6593.2012.00369.x.

Kariotis G. and Panagiotopoulos E. (2013), Applied Surveying, Tome A, General Concepts, Definitions, Disigma Publications Thessaloniki, Greece, pp.134-146. ISBN: 978-960-9495-27-1.

Kontos D.T, Komilis P.D. and Halvadakis R.C. (2003), Siting MSW landfills in Lesvos Island with a GIS-based methodology, Waste Management \& Research, 21(3), 262-277. https://doi.org/10.1177/0734242X0302100310.

Lee J. (1991), Comparison of existing methods for building triangular irregular network, models of terrain from grid digital elevation models, International Journal of Geographical Information Systems, 5(3), 267-285. https://doi.org/10.1080/02693799108927855.

Longley A.P., Goodchild F.M., Maguire J.D. and Rhind W.D. (2011), Geographic Information Systems and Science, John Wiley \& Sons Inc, 3rd Edition, ISBN 978-0-470-72144-5.

Malczewski J. (1997), Propagation of errors in multicriteria location analysis: A case study. In: Fandel G., Gal T. (eds.), Multiple Criteria Decision Making, Lecture Notes in Economics and Mathematical Systems, 448, 154-155. https://doi.org/10.1007/978-3-642-59132-7_17.

Michaels M. (1991), GIS expected to make landfill siting easier, Geographical Information Systems, p. 30-35.

Papamanolis G., Giannakopoulos E. and Kalavrouziotis I.K. (2018), Shipyards waste and sustainable management in Greece: case study, Desalination and Water Treatment, 127, 90-96.

Peucker T.K., Fowler R.J., Little J.J. and Mark D.M. (1978), The triangulated irregular network. Proceedings, American Society of Photogrammetry: Digital Terrain Models (DTM) Symposium, St. Louis, Missouri, May 9-11, 1978, Falls Church, VA: American Congress on Surveying and Mapping, and American Society of Photogrammetry and Remote Sensing, pp. 516-540.

Rushbrook P. and Pugh M. (1999), Solid Waste Landfills in Middle-and Lower Income Countries. A Technical Guide to Planning, Design, and Operation. In: The International Bank For Reconstruction and Development. World Bank technical paper No. 426. ISBN 0-8213-4457-9. 
Tsouhlarakis A. and Ahileos G. (2010), Learning GIS. Disigma Publications Thessaloniki, Greece, pp. 158-161.

Van Deventer H., Nel J., Mbona N., Job N., Ewart-Smith J., Snaddon K. and Maherry A. (2015), Desktop classification of inland wetlands for systematic conservation planning in data-scarce countries: mapping wetland ecosystem types, disturbance indices and threatened species associations at country-wide scale, Aquatic Conservation 26(1), 57-75. https://doi.org/10.1002/aqc.2605.

Wu J. and Amaratunga K. (2003), Wavelet triangulated irregular networks, International Journal of Geographical Information Systems, 17(3), 273-289. https://doi.org/10.1080/1365881022000016016.

Zamorano M., Molero E., Hurtado A., Grindlay A. and Ramos A. (2008), Evaluation of a municipal landfill site in Southern Spain with GIS-aided methodology, Journal of Hazardous Materials. 160, 473-481. https://doi.org/10.1016/ j.jhazmat.2008.03.023. 